\title{
In vitro hypoglycemic effects of unripe and ripe fruits of Musa sapientum
}

\author{
Somnath Devidas Bhinge*, Mangesh Anil Bhutkar, Dheeraj Suhas Randive, \\ Ganesh Hindurao Wadkar, Tejashri Suresh Hasabe
}

Rajarambapu College of Pharmacy, Kasegaon, Dist - Sangli, Maharashtra, India

\begin{abstract}
The present study was undertaken to verify the hypoglycemic potential of unripe and ripe fruit extracts of Musa sapientum by using various in-vitro techniques, namely glucose adsorption capacity, glucose diffusion, amylolysis kinetics and glucose transport across the yeast cells. The results revealed that the unripe and ripe fruit extracts of Musa sapientum adsorbed glucose and the adsorption of glucose increased remarkably with an increase in glucose concentration. There were no significant $(p \leq 0.05)$ differences between their adsorption capacities. In the amylolysis kinetic experimental model the rate of glucose diffusion was found to be increased with time from 30 to $180 \mathrm{~min}$ and both extracts exhibited significant inhibitory effects on the movement of glucose into external solution across the dialysis membrane as compared to control. The plant extracts also promoted glucose uptake by the yeast cells and enhancement of glucose uptake was dependent on both the sample and glucose concentration. The hypoglycemic effect exhibited by the extracts was observed to be mediated by inhibiting $\alpha$-amylase, inhibiting glucose diffusion by adsorbing glucose and by increasing glucose transport across the cell membranes as revealed by an in-vitro model of yeast cells.
\end{abstract}

Keywords: Diabetes mellitus. Hypoglycemic effect/study. Glucose diffusion. Yeast cells. Musa sapientum/ effects.

\section{INTRODUCTION}

Diabetes mellitus is a metabolic disorder characterized by chronic hyperglycemia and disturbances of carbohydrate, protein and fat metabolisms, secondary to an absolute or relative lack of the hormone insulin (Bhutkar, Bhise, 2012; Bhutkar et al., 2016). There is a global increase in the prevalence of diabetes mellitus predominantly, related to lifestyles and the resulting surge in obesity (King et al., 1998). It has been estimated that about 171 million people worldwide suffer from diabetes mellitus (Roglic et al., 2004). The incidence of prediabetes and diabetes is increasing and imposes a great burden on healthcare worldwide. Patients with prediabetes and diabetes have significantly increased risk for cardiovascular diseases and other complications. Currently, management of hyperglycemia includes pharmacological interventions, physical exercise, and

\footnotetext{
*Correspondence: S. D. Bhinge. Rajarambapu College of Pharmacy, Kasegaon, Shivaji University, Kolhapur, 415404 - Kasegaon, Dist - Sangli, Maharashtra, INDIA. E-mail: somu1245@yahoo.co.in
}

change of lifestyle and diet (Deng, 2012). The use of orthodox drugs in the management of diabetes mellitus has not improved the situation. Management of diabetes without any side effects is still a challenge in the medical field, as presently available drugs for diabetes have one or more adverse effects (Bohannon, 2002). Since the existing drugs for the treatment of diabetes mellitus do not satisfy our need completely, the search for new drugs continues. Food stuffs and supplements have increasingly become attractive alternatives to prevent or treat hyperglycemia, especially in subjects with mild hyperglycemia (Bhutkar, Bhise, 2011; Deng, 2012). Therefore, there has been increasing demand for the use of plant products and food stuffs with antidiabetic activity due to low cost, easy availability and lesser side effects. Plants are well known in traditional medicine for their hypoglycaemic activities. Ayurveda, the most ancient system of medicine plays an important role for prevention and cure of diseases and for achieving and maintaining excellent health (Randive et al., 2016; Savali, Bhinge, Chittapurkar, 2011). Available literature indicates that there are more than 800 plant species showing hypoglycaemic activity (Rajagopal, 
Sasikala, 2008). However, most of traditional antidiabetic plants awaits proper scientific and medical evaluation of their ability to improve blood glucose control and or to prevent the diabetic complications (Bhutkar, Bhise, 2013). Thus, there is a vital need to undertake a systematic study so as to explore the possible mechanism(s) of action of the traditional anti-diabetic plants.

Musa sapientum belong to the Kingdom; Plantae, division; Magnoliophyta, class; Liliopsida, Order; Zingiberales, family; Musaceae, Genus; Musa, species; Musa sapietum. Musa sapientum originated mainly from intra-and interspecific hybridizations between two wild diploid species, M. acuminate Colla ('A' genome) and M. balbisiana Colla ('B' genome). (Baskar et al., 2011). The fruit of M. paradisiaca and M. sapientum has been traditionally used in diarrhoea (unripe), dysentery, intestinal lesions in ulcerative colitis, diabetes (unripe), in sprue, uremia, nephritis, gout, hypertension, cardiac disease (Mohammad, Saleha, 2011). M. sapientum is also used in the treatment of excess menstruation with Canna indica L. var. speciosa. (Partha, Hossain, 2007). It is also used in inflammation, pains and snakebite as well as it possesses antilithic, antiulcerogenic, hypoglycemic, hypolipidaemic and antioxidant actions. (Coe, Anderson, 1999; Prasad, Bharathi, Srinivasan, 1993; Lewis, Fields, Shaw, 1999; Ojewole, Adewunmi, 2003; Krishnan, Vijayalakshmi, 2005)

The present study was, therefore undertaken to verify the hypoglycemic potential of the of unripe and ripe fruit extracts of Musa sapientum by using various in-vitro techniques; namely glucose adsorption capacity, glucose diffusion, amylolysis kinetics and glucose transport across the yeast cells to have an insight about its probable mechanism(s) of action.

\section{MATERIAL AND METHODS}

\section{Chemicals and reagents}

The glucose oxidase peroxidase kit was purchased from Pathozyme Diagnostics, Kagal, Maharashtra, India. Dialysis bags (12,000 MW cutoff; Himedia laboratories, India) were used in the study. All the chemicals used in the present study were of extra pure analytical grade.

\section{Plant material}

The unripe and ripe fruit of Musa sapientum were collected from local areas of Atpadi (District Sangli, Maharashtra, India) and were further identified and authenticated by the Department of Botany, Science College, Karad, District Satara, Maharashtra, India. Thin slices of the fruits of Musa sapientum were dried in a shade, powdered and passed through 60 mesh sieve (BS) and stored in an airtight container at room temperature till further use.

\section{Preparation of plant extracts}

Powder of ripe and unripe fruits of Musa sapientum was separately extracted with $95 \%$ ethanol in a Soxhlet apparatus. The solvent was selectively removed under reduced pressure, which yielded a black sticky residue. The obtained extract was thereafter stored in a desiccator till further use.

\section{Evaluation of hypoglycemic activity of plant extracts using various in vitro methods}

\section{Determination of glucose adsorption capacity}

The samples of plant extracts (1\%) were added to $25 \mathrm{~mL}$ of glucose solution of increasing concentration $(5,10,20,50$ and $100 \mathrm{mM})$. The mixture was stirred well, incubated in a shaker water bath at $37^{\circ} \mathrm{C}$ for $6 \mathrm{~h}$, centrifuged at $4,000 \times \mathrm{g}$ for $20 \mathrm{~min}$ and the glucose content in the supernatant was determined. The concentration of bound glucose was calculated using the following formula (Ou et al., 2001).

Glucose Bound $=\frac{\mathrm{G}_{1}-\mathrm{G}_{6}}{\text { Weight of the sample }} \times$ Volume of solution

The $\mathbf{G}_{\mathbf{1}}$ is the glucose concentration of the original solution. $\mathbf{G}_{\mathbf{6}}$ is the glucose concentration after 6 hours.

Effect of plant extracts on in-vitro glucose diffusion

$25 \mathrm{~mL}$ of glucose solution $(20 \mathrm{mM})$ and the samples of plant extracts $(1 \%)$ were dialyzed in dialysis bags against $200 \mathrm{~mL}$ of distilled water at $37{ }^{\circ} \mathrm{C}$ in a shaker water bath. The glucose content in the dialysate was determined at 30,60,120 and 180 min using glucose oxidase peroxidase diagnostic kit. A control test was carried out without sample. Glucose dialysis retardation index (GDRI) was calculated by using the following formula (Ahmed et al., 2011).

$$
\text { GDRI }=100-\frac{\begin{array}{c}
\text { Glucose content with } \\
\text { additional of sample }(\mathrm{mg} / \mathrm{dl})
\end{array}}{\begin{array}{l}
\text { Glusose content of } \\
\text { the control }(\mathrm{mg} / \mathrm{dl})
\end{array}} \times 100
$$

Effect of plant extracts on in-vitro amylolysis kinetics $40 \mathrm{~g}$ of potato starch was added to $\approx 900 \mathrm{~mL}$ of 0.05 
M phosphate buffer ( $\mathrm{pH}$ 6.5). The solution after stirring at $65^{\circ} \mathrm{C}$ for $30 \mathrm{~min}$ was made up to a final volume of 1000 $\mathrm{mL}$ to give a $4 \%(\mathrm{w} / \mathrm{v})$ starch solution. $25 \mathrm{~mL}$ of the above starch solution, $\alpha$-amylase $(0.4 \%)$, and the plant extracts $(1 \%)$ were dialyzed in a dialysis bag against $200 \mathrm{~mL}$ of distilled water at $37^{\circ} \mathrm{C}(\mathrm{pH} 7.0)$ in a shaker water bath. The glucose content in the dialysate was determined at 30 , 60,120 and $180 \mathrm{~min}$. A control test was carried out without sample (Ou et al., 2001).

\section{Glucose uptake by yeast cells}

Commercial baker's yeast was washed by repeated centrifugation $(3,000 \times \mathrm{g} ; 5 \mathrm{~min})$ in distilled water until the supernatant fluids were clear and a $10 \%(\mathrm{v} / \mathrm{v})$ suspension was prepared in distilled water. Various concentrations of extracts $(1-5 \mathrm{mg})$ were added to $1 \mathrm{~mL}$ of glucose solution (5-25 mM) and incubated together for $10 \mathrm{~min}$ at $37^{\circ} \mathrm{C}$. The reaction was started by adding $100 \mu \mathrm{l}$ of yeast suspension, vortexed and further incubated at $37^{\circ} \mathrm{C}$ for $60 \mathrm{~min}$. After $60 \mathrm{~min}$, the tubes were centrifuged $(2,500$ $\times \mathrm{g}, 5 \mathrm{~min}$ ) and glucose was estimated in the supernatant. The percent increase in glucose uptake by yeast cells was calculated using the following formula (Cirillo, 1962).

Increase in glucoe uptake $=\frac{\text { Absorbance }_{\text {control }}-\text { Absorbance }_{\text {sample }}}{\text { Absorbance }_{\text {control }}} \times 100$

where, Abs control is the absorbance of the control reaction (containing all reagents except the test sample), and Abs sample is the absorbance of the test sample.

\section{Statistical analysis}

All the determinations were carried out in triplicates and the data were analyzed by ANOVA followed by Tukey's multiple comparison test for significant differences (Ahmed, Sairam, Urooj, 2011). Values were considered at $p \leq 0.05$. Graphs were plotted using Graph Pad Prism 6 software.

\section{RESULTS AND DISCUSSION}

The results of the glucose adsorption capacity exhibited by the selected plant extracts are shown in Figure 1.

The results of the studies on glucose adsorption capacity showed that the extracts of unripe and ripe fruit of $M$. sapientum could bind glucose effectively. The glucose adsorption capacity was found to be directly proportional to the glucose concentration. It was observed that the extracts of unripe and ripe fruit of $M$. sapientum were effective in adsorbing glucose at both low and higher concentrations of

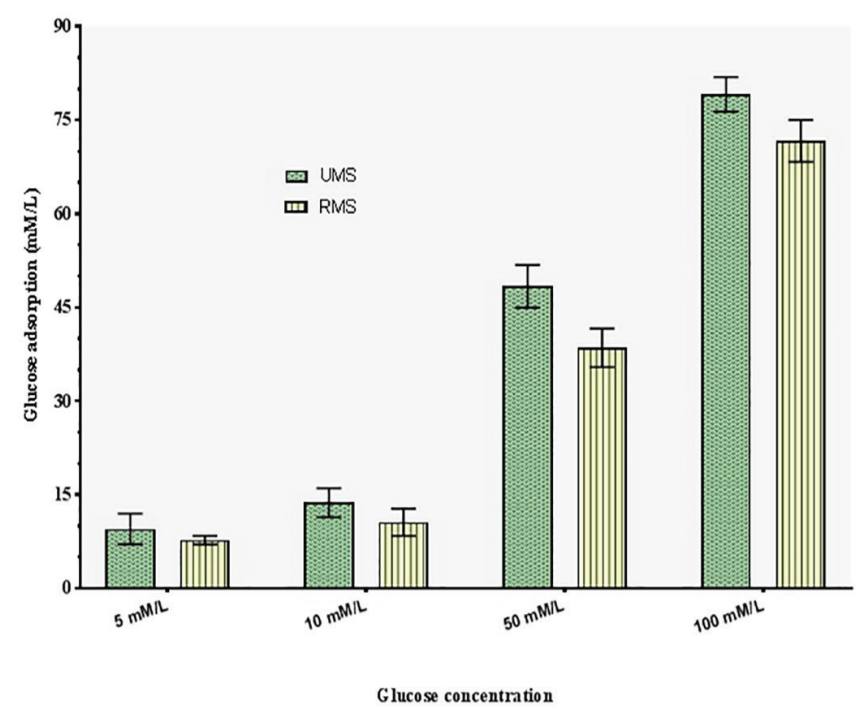

FIGURE 1 - Glucose binding capacity of extract of unripe and ripe fruit of Musa sapientum at different concentrations of glucose. (Values are mean \pm SD of triplicate determinations). Note-UMS - Unripe Musa sapientum fruit extract, RMS - Ripe Musa sapientum fruit extract.

glucose used in the study $\left(5\right.$ and $\left.100 \mathrm{mmol} \mathrm{L}^{-1}\right)$. The glucose adsorption capacity of the extracts under study was observed to be directly proportional to the molar concentration of glucose. A relatively higher amount of glucose was found to be bound with an increased glucose concentration. No significant $(p \leq 0.05)$ differences were marked between the adsorption capacities of the extract of unripe and ripe fruit of $M$. sapientum. It was also indicated from the study that the plant under study could effectively bind glucose even at lower concentrations of glucose $(5 \mathrm{mM})$ thereby decreasing the amount of glucose and retarding its transport across the intestinal lumen. Thus, the extracts effectively contribute in blunting the postprandial hyperglycemia. The present findings exhibit similarity to the observations reported for insoluble fiber-rich fractions isolated from Averrhoa carambola (Chau, Chen, Lin, 2004).

Table I highlight the results of effect extract of unripe and ripe fruit of M. sapientum on in-vitro glucose diffusion. During the present study the movement of glucose diffusion across the dialysis membrane was monitored once in 30 min till $180 \mathrm{~min}$. The rate of diffusion of glucose across the dialysis membrane was found to increase with time from 30 to $180 \mathrm{~min}$. The extracts of unripe and ripe fruit of $M$. sapientum exhibited significant inhibitory effects on movement of glucose into the external solution across the dialysis membrane as compared to control. Glucose dialysis retardation index (GDRI) was determined on the basis of the retardation of glucose diffusion. It was found that the retardation of glucose diffusion by the extract of unripe fruit 
TABLE I - Effect of selected samples on glucose diffusion and glucose dialysis retardation index

\begin{tabular}{lcccc}
\hline \multirow{2}{*}{ Sample } & \multicolumn{4}{c}{ Glucose content in dialysate $\mathbf{( m M )}$} \\
\cline { 2 - 5 } & $\mathbf{3 0} \mathbf{~ m i n}$ & $\mathbf{6 0} \mathbf{~}$ in & $\mathbf{1 2 0} \mathbf{~ m i n}$ & $\mathbf{1 8 0} \mathbf{~ m i n}$ \\
\hline Control & $0.77^{\mathrm{c}} \pm 0.01$ & $1.23^{\mathrm{c}} \pm 0.01$ & $1.63^{\mathrm{c}} \pm 0.01$ & $1.91^{\mathrm{c}} \pm 0.01$ \\
UMS & $0.47^{\mathrm{a}} \pm 0.01(38.97)$ & $1.08^{\mathrm{a}} \pm 0.01(12.20)$ & $1.36^{\mathrm{a}} \pm 0.01(16.57)$ & $1.73^{\mathrm{a}} \pm 0.01(9.43)$ \\
RMS & $0.54^{\mathrm{b}} \pm 0.01(29.88)$ & $1.14^{\mathrm{b}} \pm 0.01(7.32)$ & $1.45^{\mathrm{b}} \pm 0.01(11.05)$ & $1.80^{\mathrm{b}} \pm 0.01(5.76)$ \\
\hline
\end{tabular}

Values in parenthesis indicate glucose dialysis retardation index (GDRI). Mean values $(n=3)$ with different superscript letters in columns differ significantly from each other ( $\mathrm{p} \leq 0.05$ ). Note - UMS - Unripe Musa sapientum fruit extract, RMS - Ripe Musa sapientum fruit extract.

of $M$. sapientum was significantly higher $(p \leq 0.05)$ than the ripe fruit extract. The said effect exhibited by the extract of unripe fruit of $M$. sapientum was reflected with its higher glucose dialysis retardation index (GDRI) value than those observed for the ripe fruit extract of M. sapientum.

Table II illustrates the effects of the extract of unripe and ripe fruit of $M$. sapientum on the amylolysis kinetics model. Glucose dialysis retardation index (GDRI) which is determined on the basis of the retardation of diffusion of glucose diffusion, is considered to be an important in-vitro index to assess the effect of a fiber on the delay in glucose absorption in the gastrointestinal tract (Lopez et al., 1996). A relatively higher glucose dialysis retardation index (GDRI) indicates a higher retardation index of glucose by the sample. The glucose dialysis retardation index (GDRI) was observed to be $34.49 \%$ and $27.59 \%$ of the extract of unripe and ripe fruit of $M$. sapientum respectively at 60 min which gradually got reduced to $22.86 \%$ and $14.29 \%$ respectively at $120 \mathrm{~min}$. The retardation of diffusion of glucose may also be due to the inhibition of the enzyme, $\alpha$-amylase by the extracts under study thereby reducing the release of glucose from the starch. The inhibitors of carbohydrate hydrolyzing enzymes promote a delay in the digestion of carbohydrate thereby prolonging the overall carbohydrate digestion time to cause a reduction in the rate of absorption of glucose and consequently blunting the postprandial plasma glucose rise (Bailey, 2003). Our findings suggest that the inhibition of $\alpha$-amylase enzyme may be one of the probable mechanisms through which the extract of unripe and ripe fruit of $M$. sapientum exerts their hypoglycemic effect. Several inhibitors of alpha amylase enzyme have been recently developed from natural sources and some of them in clinical use are acarbose, miglitol and voglibose (Ali, Houghton, Soumyanath, 2006).

Figure 2 and Figure 3 highlights the rate of glucose transport across cell membrane in the yeast cells system exhibited by the extract of unripe and ripe fruit of $M$. sapientum respectively. The mechanism of transport of glucose across the yeast cell membrane has received attention and has been considered as an important technique for in-vitro screening of hypoglycemic activity of various compounds/medicinal plants. The results of the study revealed that both the extracts under study promoted transport of glucose across the yeast cells.

The amount of glucose, which remains in the medium after a specific time interval acts as a measure of the glucose uptake by the yeast cells. The rate of uptake of glucose into the yeast cells was found to be linear in all the 5 glucose concentrations used in this study. The extract of unripe fruit of $M$. sapientum exhibited significantly higher $(p \leq 0.05)$ activity than the extract of ripe fruit of $M$. sapientum at all concentrations used in the study. The percent increase in the uptake of glucose by the yeast cells was found to be inversely proportional to the concentration

TABLE II - Effect of selected samples on starch digestibility and glucose dialysis retardation index

\begin{tabular}{lcccc}
\hline \multirow{2}{*}{ Sample } & \multicolumn{4}{c}{ Glucose content in dialysate $\mathbf{( m M )}$} \\
\cline { 2 - 5 } & $\mathbf{3 0} \mathbf{~ m i n}$ & $\mathbf{6 0} \mathbf{~ m i n}$ & $\mathbf{1 2 0} \mathbf{~ m i n}$ & $\mathbf{1 8 0} \mathbf{~ m i n}$ \\
\hline Control & 0.0 & $0.29^{\mathrm{c}} \pm 0.01$ & $0.35^{\mathrm{c}} \pm 0.01$ & $0.45^{\mathrm{c}} \pm 0.01$ \\
UMS & $0.0(100)$ & $0.19^{\mathrm{a}} \pm 0.01(34.49)$ & $0.27^{\mathrm{a}} \pm 0.01(22.86)$ & $0.36^{\mathrm{a}} \pm 0.01(20.0)$ \\
RMS & $0.0(100)$ & $0.21^{\mathrm{b}} \pm 0.01(27.59)$ & $0.30^{\mathrm{b}} \pm 0.01(14.29)$ & $0.41^{\mathrm{b}} \pm 0.01(8.88)$ \\
\hline
\end{tabular}

Values in parenthesis indicate glucose dialysis retardation index (GDRI). Mean values $(n=3)$ with different superscript letters in columns differ significantly from each other ( $\mathrm{p} \leq 0.05$ ). Note - UMS - Unripe Musa sapientum fruit extract, RMS - Ripe Musa sapientum fruit extract. 


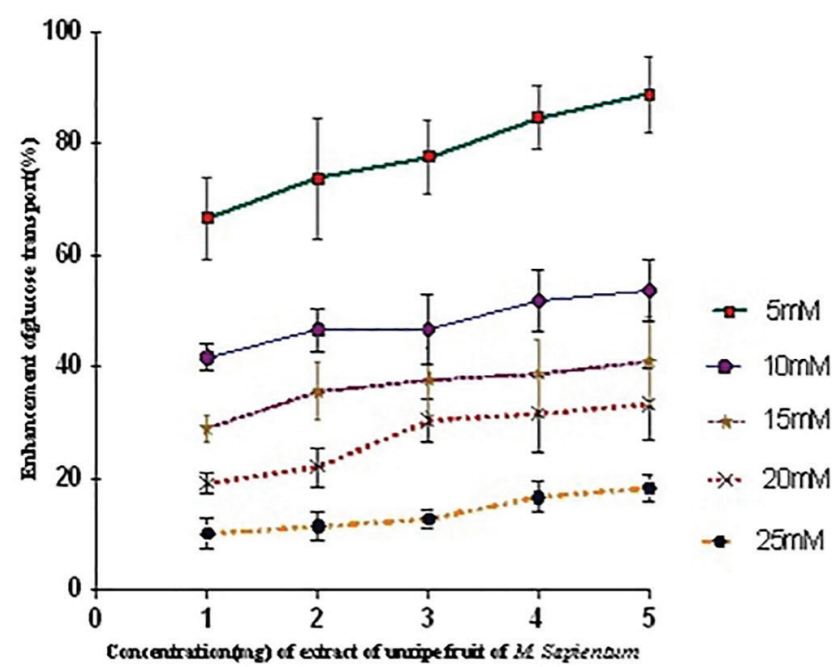

FIGURE 2 - Effect of extract of unripe fruit of Musa sapientum on the uptake of glucose by yeast cells. (Values are mean \pm SD of triplicate determinations).

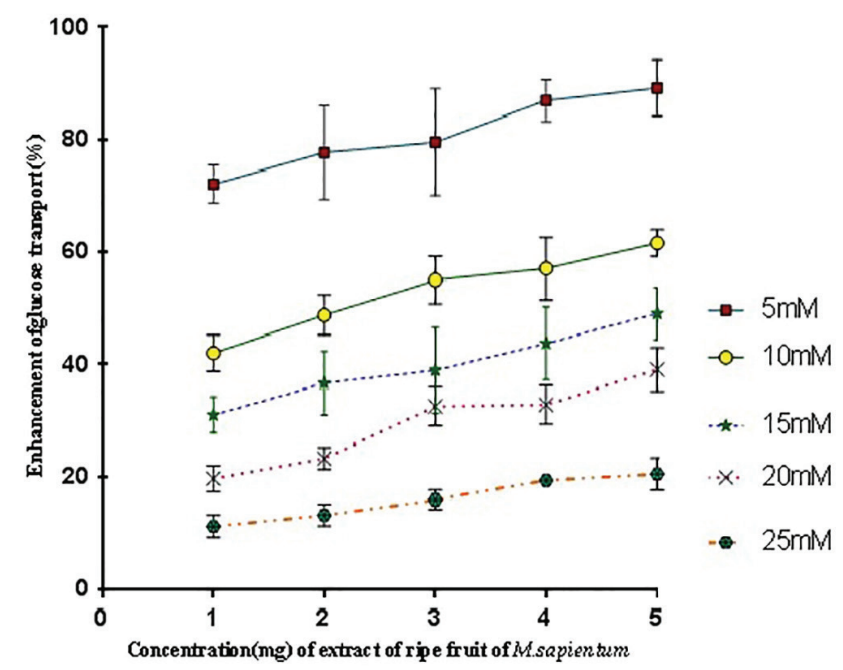

FIGURE 3 - Effect of extract of ripe fruit of Musa sapientum on the uptake of glucose by yeast cells. (Values are mean \pm SD of triplicate determinations).

of glucose and got decreased with an increase in the molar concentration of the glucose solution. Previous studies involving the transport of non-metabolizable sugars, metabolizable glycosides have suggested that the transport of sugar across the yeast cell membrane is mediated by stereo specific membrane carriers and usually takes place by the process of facilitated diffusion (Illiano, Cuatrecasas, 1971; Teusink et al., 1998).

\section{CONCLUSION}

In conclusion, the results of the present investigation highlighted the hypoglycemic activity of extract of unripe and ripe fruit of $M$. sapientum as assessed by various invitro methods. Inspite of the fact that in-vitro screening is not a reliable predictor of hypoglycemic effect in-vivo, the various model systems used in the present study provides an insight on the possible mechanisms by which the extracts of unripe and ripe fruit of M. sapientum may contribute to lowering the postprandial glucose levels. The hypoglycemic effect exhibited by the unripe and ripe fruit extract of $M$. sapientum was observed to be mediated by increasing glucose adsorption, decreasing glucose diffusion rate and at the cellular level by promoting the transport of glucose across the cell membrane as highlighted by employing simple in-vitro model of yeast cells. These observed effects further, need to be confirmed by employing different in vivo models and clinical trials which may contribute for their effective utilization as an adjunct in effective management of diabetes mellitus.

\section{CONFLICT OF INTEREST STATEMENT}

We declare that we have no conflict of interest.

\section{ACKNOWLEDGEMENT}

The authors are grateful to the Principal, Rajarambapu College of Pharmacy, Kasegaon for providing all the research facilities.

\section{REFERENCES}

Ahmed F, Sairam S, Urooj A. In vitro hypoglycemic effects of selected dietary fibre sources. J Food Sci Technol. 2011;48(3):285-289.

Ali H, Houghton P, Soumyanath A. $\alpha$-amylase inhibitory activity of some malaysian plants used to treat diabetes; with particular reference to Phyllanthus amarus. J Ethnopharmacol. 2006;107(3):449-455.

Bailey C. New approaches to the pharmacotherapy of diabetes. In: Pickup JC, William G. (editors). Textbook of Diabetes. Oxford: Blackwell Science; 2003. p. 1-73.

Baskar R, Shrisakthi S, Sathyapriya B, Shyammpriya R, Nithya R, Pongodi P. Antoxidant potential of peel extracts of banana varieties (Musa sapientum). Food Nutr Sci. 2011;2:1128-1133.

Bhutkar MA, Bhinge SD, Randive DS, Wadkar GH. Hypoglycemic effects of Berberis aristata and Tamarindus indica extracts in vitro. Bull Fac Pharm, Cairo Univ. In press 2016. Doi: http://dx.doi.org/10.1016/j.bfopcu.2016.09.001. 
Bhutkar MA, Bhise SB. Studies on antiglycation potential of some traditional antidiabetic plants. Asian J Plant Sci Res. 2013;3(6):60-63.

Bhutkar MA, Bhise SB. In vitro assay of alpha amylase inhibitory activity of some indigenous plants. Int J Chem Sci. 2012;10(1):457-462.

Bhutkar MA, Bhise SB. Spices and condiments in the management of diabetes mellitus. Res J Pharm Technol. 2011;4(1):1-6.

Bohannon NJV. Treating dual defects in diabetes: Insulin resistance and insulin secretion. Am J Health-Syst Pharm. 2002;59(9):9-13.

Chau $\mathrm{CF}$, Chen $\mathrm{CH}$, Lin $\mathrm{CY}$. Insoluble fiber-rich fractions derived from Averrhoa carambola: hypoglycemic effects determined by in vitro methods. Lebensm Wiss Technol. 2004;37(3):331-335.

Cirillo VP. Mechanism of glucose transport across the yeast cell membrane. J Bacteriol. 1962;84:485-491.

Coe FG, Anderson GJ. Ethnobotany of the sumu (ulwa) of southeastern nicaragua and comparisons with miskitu plant lore. Econ Bot. 1999;53(4):363-386.

Deng R. A review of the hypoglycemic effects of five commonly used herbal food supplements. Recent Pat Food Nutr Agric. 2012;4(1):50-60.

Illiano G, Cuatrecasas P. Glucose transport in fat cell membranes. J Biochem. 1971;246:2472-2479.

King H, Aubert RE, Herman WH. Global burden of diabetes: prevalence, numerical estimates and projections. Diabetes Care. 1998;21(9):1414-1431.

Krishnan K, Vijayalakshmi NR. Alterations in lipids and lipid peroxidation in rats fed with flavonoid rich fraction of banana (Musa paradisiaca) from high background radiation area. Indian J Med Res. 2005;122(6):540-546.

Lewis DA, Fields WN, Shaw GP. A natural flavonoid present in unripe plantain banana pulp (musa sapientum L. var. paradisiaca) protects the gastric mucosa from aspirin-induced erosions. J Ethnopharmacol. 1999;65(3):283-288.
Lopez G, Ros G, Rincon F, Periago MJ, Martinez MC, Ortuno J. Relationship between physical and hydration properties of soluble and insoluble fiber of artichoke. J Agric Food Chem. 1996;44(9):2773-2778.

Mohammad ZI, Saleha A. Musa paradisiaca L. and Musa sapientum L.: A phytochemical and pharmacological review. J Appl Pharm Sci. 2011;1(5):14-20.

Ojewole, JA, Adewunmi CO. Hypoglycemic effect of methanolic extract of Musa paradisiaca (Musaceae) green fruits in normal and diabetic mice. Methods Find Exp Clin Pharmacol. 2003;25(6):453-456.

Ou S, Kwok KC, Li Y, Fu L. In vitro study of possible role of dietary fiber in lowering postprandial serum glucose. J Agri Food Chem. 2001;49(2):1026-1029.

Partha P, Hossain ABME. Ethnobotanical investigation into the Mandi Ethnic Community in Bangladesh. Bangladesh J Plant Taxon. 2007;14(2):129-145.

Prasad KV, Bharathi K, Srinivasan KK. Evaluation of Musa (paradisiaca Linn. cultivar) "puttubale" stem juice for antilithiatic activity in albino rats. Indian J Physiol Pharmacol. 1993;37(4):337-341.

Rajagopal K, Sasikala S. Anti-hyperglycaemic and antihyperlipidaemic effects of nymphaca stellate in alloxan induced diabetic rats. Singapore Med J. 2008;49(2):137-141.

Randive DS, Bhinge SD, Wadkar GH, Sayyad SF, Bhutkar MA. Comparative standardization of marketed formulations of fermented biomedicine - Arjunaristha. Indonesian J Pharm. 2016;27(4):220-225.

Roglic G, Wild S, Green A, Sicree R, King H. Global prevalence of diabetes: estimates for the year 2000 and projections for 2030 . Diabetes Care. 2004;27(5):1047-1053.

Savali A, Bhinge S, Chittapurkar H. Evaluation of hair growth promoting activity of Musa Paradisiaca unripe fruit extract. J Nat Pharm. 2011;2(3):120-124.

Teusink B, Diderich JA, Westerhoff HV, Van DK, Walsh MC. Intracellular glucose concentration in derepressed yeast cells consuming glucose is high enough to reduce the glucose transport rate by 50\%. J Bacteriol. 1998;180(3):556-562.

Received for publication on $07^{\text {th }}$ November 2016 Accepted for publication on $03^{\text {rd }}$ April 2017 